\title{
Investigation on Main Radiation Source at Operation Floor of Fukushima Daiichi Nuclear Power Station Unit 4
}

\author{
Hideo Hirayama ${ }^{1,2 *}$, Kenjiro Kondo ${ }^{1,2}$, Seishiro Suzuki ${ }^{1}$, Shimpei Hamamoto ${ }^{1,3}$, Kohei Iwanaga ${ }^{1}$ \\ ${ }^{1}$ Nuclear Regulation Authority, 1-9-9, Roppongi, Minato-ku, Tokyo, Japan 106-8450 \\ ${ }^{2}$ High Energy Accelerator Research Organization, 1-1, Oho, Tsukuba-shi, Ibaraki, Japan 305-0801 \\ ${ }^{3}$ Japan Atomic Energy Agency, (765-1 Funaishikawa, Tokai-mura, Naka-gun, Ibaraki 319-1184, Japan (Current affiliation) \\ *Corresponding Author: hideo.hirayama@kek.jp
}

\begin{abstract}
Pulse height distributions were measured using a $\mathrm{LaBr}_{3}$ detector set in a $1 \mathrm{~cm}$ lead collimator to investigate main radiation source at the operation floor of Fukushima Daiichi Nuclear Power Station Unit 4. It was confirmed that main radiation source above the reactor well was Co-60 from the activated steam dryer in the DS pool (Dryer-Separator pool) and that at the standby area was Cs-134 and Cs-137 from contaminated buildings and debris at the lower floor. Full energy peak count rate of Co- 60 was reduced about $1 / 3$ by $12 \mathrm{~mm}$ lead sheet placed on the floor of the fuel handling machine.
\end{abstract}

\section{KEYWORDS: Unit 4, Fukushima Daiichi, LaBr, pulse height distribution}

\section{Introduction}

Ambient dose equivalent rates at the operation floor of Fukushima Daiichi Nuclear Power Station Unit 4 were far lower than those at Unit 1,2 and 3 due to the fact that Unit 4 was under a periodical inspection at the time of the accident, March 2011. However, there were several places at which ambient dose equivalent rates exceeded several hundreds $\mu \mathrm{Sv} / \mathrm{h}$ even in this situation. This level is still higher at the position of the manual fuel removal operation. Before our measurement, Tokyo Electric Power Company had a plan to set a shielding wall at the north end of the cover of the operation floor by regarding that photons at the operation floor of Unit 4 mainly came from the contamination at the operation floor of Unit 3. If this assumption was correct, dose rates were supposed to decrease gradually depending on the distance from the north end on the operation floor of Unit 4 , by considering the distance from the Unit 3.
However, dose rate decreased rapidly depending on the distance. From this tendency, we supposed that there were other radiation sources around Unit 4. Pulse height distribution measurements were performed to investigate radiation sources for the dose at various places on the operation floor.

\section{Measurements}

A $\mathrm{LaBr}_{3}$ detector with 2 inches diameter and 2 inches length (Inspector $1000^{1)}$ ) was used for pulse height distribution measurements. Detector set inside a lead box with $1 \mathrm{~cm}$ thick and $1 \mathrm{~cm}$ diameter hole at the center was used to measure at the places at which dose rates were over $100 \mu \mathrm{Sv} / \mathrm{h}$ and to get information of photon direction. Bird-eye view of the Unit 4 reactor building operation floor and the points of measurement are shown in Figure 1.

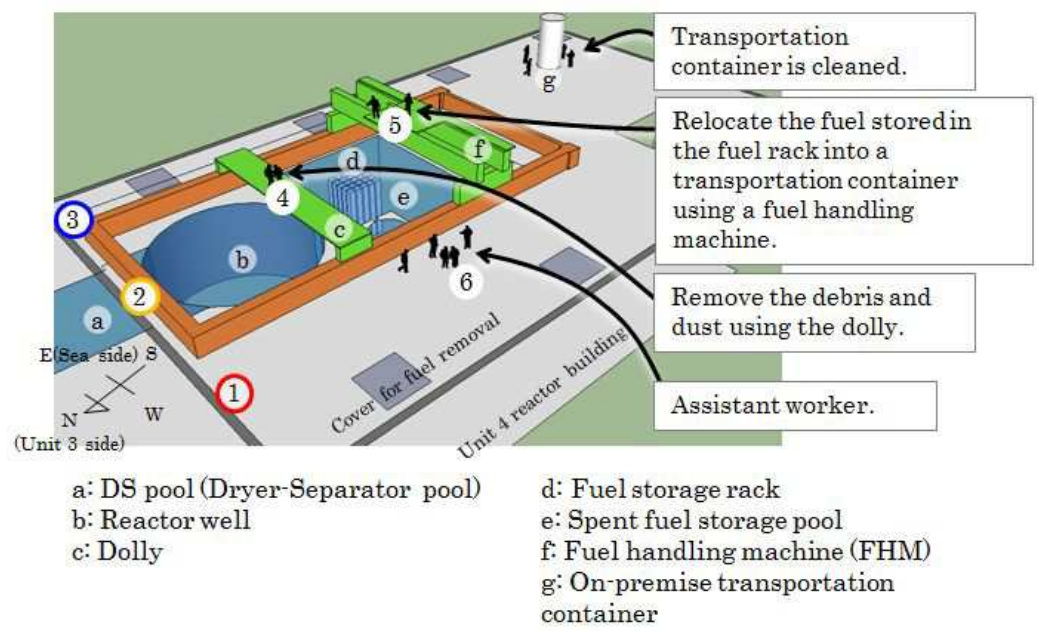

Figure 1: Bird-eye view of the Unit 4 reactor building operation floor 


\section{Results and discussions}

\section{Pulse height distribution}

Measured pulse height distributions at point 1,2 and 3 are shown in Figure 2. At the point 2, full energy absorption peaks of Co-60 were clearly seen and those of Cs-134 and Cs-137 were very small. On the other hand, full energy absorption peaks of Cs-134 and Cs-137 were dominant and those of Co-60 were relatively small at other points.

At Unit 4, the steam dryer was set on the separator in the DS pool (Dryer-Separator pool) for replacing the shroud and the top of the steam dryer cropped out from water surface. From this configuration, the steam dryer which was heavily contaminated by Co-60 could be seen via water in the reactor well. The steam dryer could not be seen directly from other 2 points. From this result, it can be confirmed that source of Co-60 is the steam dryer in the DS pool.

Ambient dose equivalent rates at $5 \mathrm{~m}$ height at the operation floor of Unit 3 was maximum at the center of the shield plug ${ }^{2)}$. If photons emitted from Cs-134 and Cs-137 came from Unit 3 with similar distribution at the operation floor of Unit 3, peak count rates at the point 2 must be higher than those at other 2 points. The small peak count rates of Cs-134 and Cs-137 at point 2 can be explained if photons from Cs-134 and Cs-137 came from depositions at the lower floors outside the North end cover of Unit 4 and were shielded by water in the DS pool.

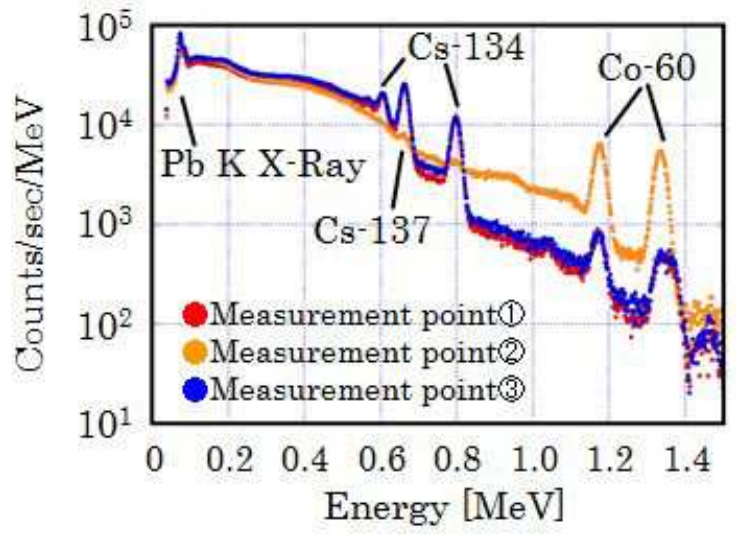

Figure 2: Comparison of pulse-height distribution
The decrease of photons from Co-60 at points 1 and 3 was supposed due to shielding effect by the operation floor.

\section{Floor shielding effect}

The shielding wall at the north end was supposed to be effective for photons from Cs-134 and Cs-137 contaminated debris at the lower floors. On the other hand, this wall was considered not to be effective for Co-60 photons from the steam dryer because they penetrate water under the wall and reach the working place.

We investigated the shielding effect of lead sheet set at the FHM floor and its dolly floor. Figure 3 shows the study point of the shielding effect. Full energy peak count rates of photons from Co-60, Cs-134 and Cs-137 were compared with or without a $12 \mathrm{~mm}$ lead sheet at the points 4,5 and 6 . The obtained results are shown in Figure 4.

At the FHM floor and the dolly floor, peak count rates of Co- 60 were reduced to about $1 / 3$ by the $12 \mathrm{~mm}$ lead sheet. This result shows that the floor shield is effective to reduce exposur dose for workers above the FHM or the dolly.

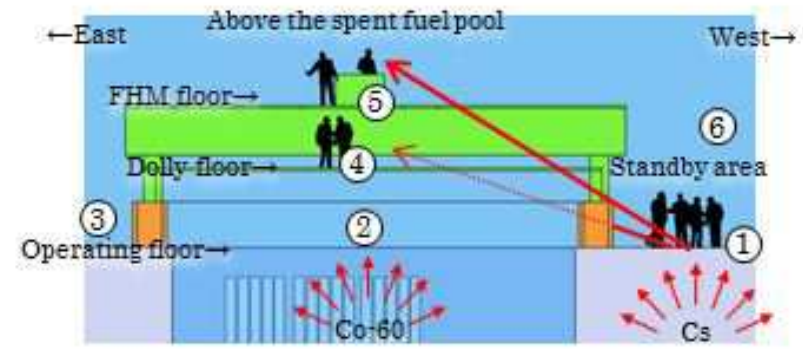

Figure 3: Study point of floor shielding effect

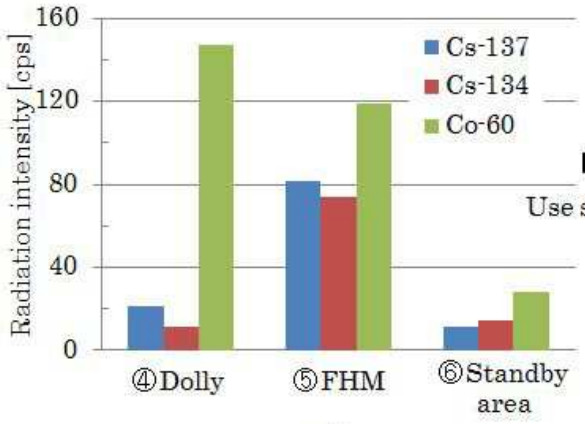

(a)
Sheet thickness of $12 \mathrm{~mm} \mathrm{~Pb}$ placed on the floor reduces gamma rays to about $1 / 3$ of its original intensity.

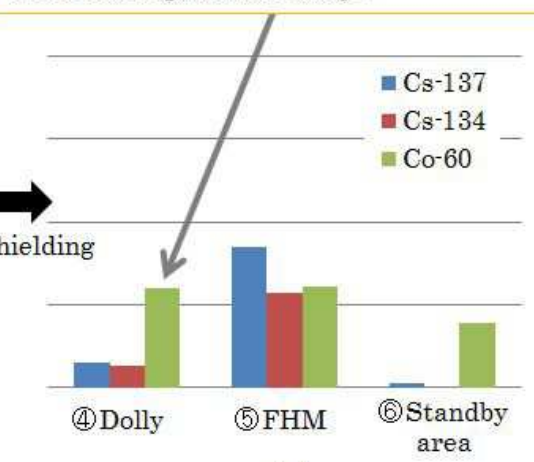

(b)

Figure 4: Reduction of peak count rates due to $12 \mathrm{~mm}$ lead 


\section{Ambient dose equivalent contribution from Unit 3}

From pulse height distributions, it became clear that contributions from the operation floor of Unit 3 were small at least for unscattered photons. High contaminations at the operation floor of Unit 3 were supposed to increase ambient dose equivalent rate at the operation floor of Unit 4 in the form of skyshine. These skyshine photons were supposed to be well shielded by the wall and the ceiling board of the operation floor due to their lower energy.

\section{Conclusion}

From our measurements, it became clear that photons emitted from Cs-134 and Cs-137 came mainly from contaminated buildings and debris at the lower floors of Unit 4 and those from Co-60 came from the steam dryer in the DS pool. At the FHM floor and the dolly floor, peak count rates of Co- 60 were reduced to about $1 / 3$ by the 12 $\mathrm{mm}$ lead sheet and these floor shields are effective to reduce exposure doses for workers above the FHM or the dolly.

\section{References}

1) CANBERRA Cooperate, InSpector ${ }^{\mathrm{TM}} 1000$ Digital Hand-Held Multichannel Analyzer, $<$ http://www.canberra.com/products/hp_radioprotection/in spector-1000.asp > (Confirmed January 27, 2016).

2) METI, First Secretariat meeting of the Team for Countermeasures for Decommissioning and Contaminated Water Treatment, Material 4-5, December 26,2013, "Results of dose rate measurement after removing small debris above the reactor well",

$<$ http://www.meti.go.jp/earthquake/nuclear/pdf/131226/131 226_01hh.pdf> (Confirmed January 27, 2016) (in Japanese). 